\title{
NGHIÊN CỨU VÀ CHẾ TẠO ĐẾ TĂNG CƯờNG TÍN HIỆU RAMAN BỀ MăT - SERS ZnO CÓ CẤU TRÚC NANO/NANO Ag TRÊN CHẤT RHODAMINE 6G
}

\author{
Lê Thị Minh Huyền ${ }^{1}$, Nguyễn Hương Giang², Đào Anh Tuấn ${ }^{3}$, Phạm Trần Tuấn ${ }^{3}$ \\ Vũ Hoàng $\mathbf{U y}^{3}$, Nguyễn Hoàng Việt ${ }^{3}$, Lê Vũ Tuấn Hùng ${ }^{3}$ \\ ${ }^{1}$ Khoa Khoa hoc Co bản, Đại hoc Y Dược Tp. Hồ Chí Minh \\ ${ }^{2}$ Trung Tâm Kiểm Nghiệm Thuốc Mỹ Phẩm, Thực Phẩm Tp. Hồ Chí Minh - \\ Ban quản lý An toàn Thực phẩm Tp. Hồ Chí Minh \\ ${ }^{3}$ Khoa Vật lý - Vật lý Kỹ thuật, Truờng Đại học Khoa hoc Tụ nhiên, \\ Đại học Quốc gia Tp. Hồ Chí Minh
}

(Ngày đến tòa soạn: 4/7/2019; Ngày sủa bài sau phản biện: 12/8/2019;

Ngày chấp nhận đăng: 30/8/2019)

\section{Tóm tắt}

Trong những năm gần đây, các nhà khoa học đang tập trung nghiên cứu phương pháp tăng cường tín hiệu Raman bằng hiệu ứng cộng hưởng plasmon bề mặt - SERS. Phương pháp này có thể phát hiện ra các hóa chất tồn dư có trong thuốc bảo vệ thực vật với nồng độ rất nhỏ, do vậy giúp nhận dạng các phân tử ở nồng độ rất thấp, nhưng vẫn đảm bảo không phá hủy mẫu hay làm phai màu chất đo. Vì vậy, phương pháp SERS mở ra một bước tiến mới trong nghiên cứu các ngành vật lý, khoa học vật liệu, chẩn đoán y khoa, nhận dạng các loại thuốc mới... Trong đề tài này, chúng tôi tập trung nghiên cứu chế tạo vật liệu $\mathrm{ZnO}$ có cấu trúc nano bằng phương pháp phún xạ magnetron $\mathrm{DC}$, sau đó biến tính hạt nano $\mathrm{Ag}$ lên bề mặt $\mathrm{ZnO}$ bằng phương pháp phún xạ magnetron $\mathrm{DC}$, từ đó có thể đánh giá đế $\mathrm{SERS} \mathrm{ZnO} / \mathrm{Ag}$ qua chất thử Rhodamine $6 \mathrm{G}$ ở nồng độ thấp. Kết quả thu được hệ số khuếch đại $\mathrm{EF}>10^{6}$.

Tù̀ khóa: SERS, Rhodamine 6G, phún xạ magnetron DC, nano Ag, ZnO.

\section{1. ĐĂT VẤN ĐỀ}

Quang phổ Raman xuất hiện khi mẫu được chiếu xạ bởi chùm laser có tần số $\mathrm{u}_{0}$, chùm tán xạ thu được có tần số $v_{0} \pm v_{m}$ gọi là tán xạ Raman, trong đó $u_{m}$ là tần số dao động của phân tử. Mặc dù cường độ tán xạ Raman thu được rất yếu; nhưng việc ghi nhận được tín hiệu Raman của mẫu sẽ nhận biết được phân tử (có tần số dao động $\mathrm{u}_{\mathrm{m}}$ ) có trong mẫu [1]. Để khuếch đại tín hiệu Raman, các nhà nghiên cứu đã sử dụng kỹ thuật plasmonic - dựa trên sự tương tác giữa trường điện từ và các electron tự do trong kim loại. Các electron tự do trên bề mặt kim loại đồng loạt dao động khi chịu tác động bởi trường điện từ của ánh sáng, hiện tượng này gọi là plasmon bề mặt. Khi bề mặt kim loại lớn, các electron tự do phản xạ ánh sáng chiếu đến chúng. Nhưng khi kim loại có kích thước chỉ vài nanomet, các electron tự do bị giới hạn trong một không gian rất nhỏ, hạn chế tần số mà chúng có thể dao động. Tần số cụ thể của dao động này, phụ thuộc vào kích thước của các phân tử nano kim loại. Trong hiện tượng cộng hưởng, plasmon chỉ hấp thụ một phần ánh sáng tới mà dao động với cùng tần số với tần số plasmon (phản xạ phần còn lại) [4]. Việc ứng dụng kỹ thuật plasmonic trong quang phổ Raman đã khuếch đại tín hiệu Raman bề mặt, hiệu ứng này được gọi là SERS (Surface - Enhanced Raman Spectroscopy), do kỹ thuật này giúp nhận dạng các phân tử ở nồng độ rất thấp. Trong hiệu ứng SERS, các phân tử của chất

\footnotetext{
${ }^{1}$ Tel: 0908544584 Email:ximuoi2412@yahoo.com
} 
cần phát hiện thường phải được hấp phụ trên bề mặt kim loại, hoặc ít nhất là rất gần với bề mặt kim loại (tối đa $10 \mathrm{~nm}$ ) [2].

Tín hiệu Raman thu được trong phương pháp SERS phụ thuộc vào bản chất và tình trạng bề mặt của chất nền. Đối với chất nền là các kim loại quý như $\mathrm{Pt}, \mathrm{Au}, \mathrm{Ag}$ sẽ cho tín hiệu Raman tốt, và bề mặt lớp đế kim loại càng gồ ghề thì hiệu ứng plasmon bề mặt càng thể hiện rõ. Trong thời gian gần đây, các nghiên cứu về kỹ thuật SERS đều tập trung nghiên cứu chế tạo ra các đế có bề mặt gồ ghề là những thanh nanorod, nanobelt [7],... nhằm tăng diện tích bề mặt hiệu dụng, từ đó ghi nhận được tín hiệu plasmon bề mặt của những mẫu thử có nồng độ rất nhỏ $[3,8,9,10]$. Ngoài ra, hiệu ứng SERS sẽ đạt hiệu quả cao hơn nhiều khi có sự hỗ trợ của lớp bán dẫn. ZnO là một trong những lựa chọn tốt để tạo ra đế bán dẫn trong hiệu ứng SERS này $[5,6,7]$. ZnO là chất bán dẫn có độ rộng vùng cấm lớn $(\mathrm{Eg}=3,3 \mathrm{eV}$ ở nhiệt độ phòng), năng lượng liên kết exciton khoảng $60 \mathrm{meV}$ và là chất ít độc hại trong quá trình chế tạo và sử dụng, công nghệ chế tạo không quá phức tạp, chi phí giá thành thấp.

Trong các loại hóa chất được sử dụng để đánh giá chất lượng của đế SERS, chất thử Rhodamine $6 \mathrm{G}$ được các nhà khoa học dùng nhiều nhất. Rhodamine $6 \mathrm{G}$ (có công thức phân tử $\mathrm{C}_{28} \mathrm{H}_{31} \mathrm{~N}_{2} \mathrm{O}_{3} \mathrm{Cl}$ ) là thuốc nhuộm màu công nghiệp, cực kỳ độc hại, có thể tan trong nước, methanol và ethanol, bị cấm dùng trong sản xuất thực phẩm. Tại Việt Nam, Rhodamine $6 \mathrm{G}$ đã được sử dụng một cách bất hợp pháp để nhuộm màu thực phẩm, làm cho thực phẩm trở thành có màu đỏ ví dụ như bột ớt, ruốc, hạt dưa,... Chất này tích tụ lâu ngày trong cơ thể sẽ gây thương tổn đến gan, thận và dẫn đến ung thư. Ngoài ra, Rhodamine $6 \mathrm{G}$ còn được sử dụng để nhuộm vải. Người sử dụng vải có nhuộm chất này sẽ mắc các bệnh về da, thậm chí bị ung thư da. Vì Rhodamine $6 \mathrm{G}$ gây ảnh hưởng nghiêm trọng đến sức khỏe của con người nên việc phát hiện sự tồn dư của Rhodamine $6 \mathrm{G}$ trong thực phẩm là rất quan trọng và cấp thiết.

Trong đề tài này, chúng tôi tập trung nghiên cứu chế tạo vật liệu $\mathrm{ZnO}$ có cấu trúc nano bằng phương pháp phún xạ magnetron $\mathrm{DC}$, sau đó biến tính hạt nano $\mathrm{Ag}$ lên bề mặt đế cũng bằng phương pháp này, từ đó có thể phát hiện chất thử Rhodamine $6 \mathrm{G}$.

Tín hiệu Raman của các mẫu được ghi bằng máy quang phổ kế Raman (Micro-Raman) với laser kích thích có bước sóng $532 \mathrm{~nm}$. Bên cạnh đó, cấu trúc tinh thể, hình thái bề mặt và tính chất quang của các mẫu cũng được xác định bằng kính hiển vi điện tử quét SEM (Hitachi 4700), máy quang phổ nhiễu xạ tia X (XRD) (Bruker D8 Advance), thiết bị quang phổ hấp thụ phân tử (UV-Vis) (Model PB - 10, power 200W, Taiwan).

\section{THÍ NGHIÊM}

Để tạo được một đế xốp, có bề mặt gồ ghề, đầu tiên, màng $\mathrm{ZnO}$ được chế tạo trên đế thủy tinh bằng phương pháp phún xạ magnetron $\mathrm{DC}$ ở điều kiện áp suất $6.10^{-3}$ torr từ bia $\mathrm{Zn}$ (độ tinh khiết 99\%), khoảng cách từ bia đến đế là $7 \mathrm{~cm}$, công suất dòng $60 \mathrm{~W}$, trong khoảng thời gian 15 phút, trong môi trường hỗn hợp khí $\mathrm{Ar}$ và $\mathrm{O}_{2} 20 \%$. Sau khi chế tạo, màng $\mathrm{ZnO}$ xốp được nung ở nhiệt độ $500^{\circ} \mathrm{C}$ trong 3 giờ để tăng cường hàm lượng $\mathrm{O}_{2}$ cho màng $\mathrm{ZnO}$. Sau đó, sử dụng phương pháp phún xamagnetron $\mathrm{DC}$ để biến tính $\mathrm{Ag}$ lên đế $\mathrm{ZnO}$ với điều kiện dòng $15 \mathrm{~mA}$, trong 60 giây; ủ nhiệt $400^{\circ} \mathrm{C}$ trong môi trường $\mathrm{Ar}$ trong 15 phút, áp suất $10^{-3}$ torr. Các đế SERS $\mathrm{ZnO} / \mathrm{Ag}$ được nhỏ Rhodamine $6 \mathrm{G}$ với nồng độ $10^{-5} \mathrm{M}$ và kiểm tra hiệu ứng SERS.

Cấu trúc tinh thể, hình thái bề mặt và tính chất quang của mẫu $\mathrm{ZnO}, \mathrm{ZnO} / \mathrm{Ag}$ được xác định bằng máy nhiễu xạ tia $\mathrm{X}(\mathrm{XRD})$ (Bruker $\mathrm{D} 8$ Advance), kính hiển vi điện tử quét $\mathrm{SEM}$ (Hitachi 4700) - EDS mapping, tính chất quang của đế SERS được đo bằng thiết bị quang phổ hấp thụ UV-Vis (Model PB - 10, power 200W, Taiwan). Tín hiệu Raman của các mẫu $\mathrm{ZnO}$ và $\mathrm{ZnO} / \mathrm{Ag}$ sau khi được nhỏ một lượng $50 \mu \mathrm{L}$ dung dịch Rhodamine $6 \mathrm{G}$ được ghi bằng máy quang phổ kế Raman (Micro-Raman) với laser kích thích có bước sóng $532 \mathrm{~nm}$. 
3. KẾT QUẢ VÀ THẢO LUẬN

Sau khi chế tạo màng mỏng $\mathrm{ZnO}$ bằng phương pháp phún xạ magnetron $\mathrm{DC}$ với bia $\mathrm{Zn}$, sau đó được nung nóng ở nhiệt độ $500^{\circ} \mathrm{C}$ trong 3 giờ. Kết quả chụp ảnh SEM bề mặt cho thấy các màng $\mathrm{ZnO}$ chế tạo khá xốp, độ lồi lõm phân bố đồng đều trên mặt đế (hình 1).

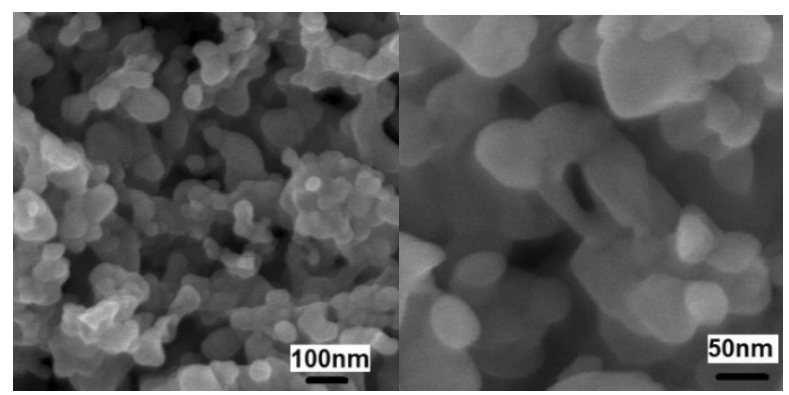

Hinh 1. Anh SEM bề mặt màng ZnO xốp được chế tạo bằng phương pháp phún xa magnetron $D C$

Sau đó, chúng tôi đã biến tính nano Ag lên màng $\mathrm{ZnO}$ để tạo thành các đế SERS. Kết quả ảnh SEM bề mặt của $\mathrm{ZnO} / \mathrm{Ag}$ cho thấy lớp $\mathrm{Ag}$ phân bố khá đều trên bề mặt $\mathrm{ZnO}$, bề dày lớp $\mathrm{Ag}$ khá mỏng và kết tụ thành hạt có đường kính khoảng $<50 \mathrm{~nm}$ hình $2(\mathrm{a}, \mathrm{b})$. Ảnh $\mathrm{SEM}$ cắt lớp cũng cho thấy các hạt $\mathrm{Ag}$ có kích thước nhỏ hơn $50 \mathrm{~nm}$ bám trên bề mặt $\mathrm{ZnO}$ (hình $2 \mathrm{c}$ ).

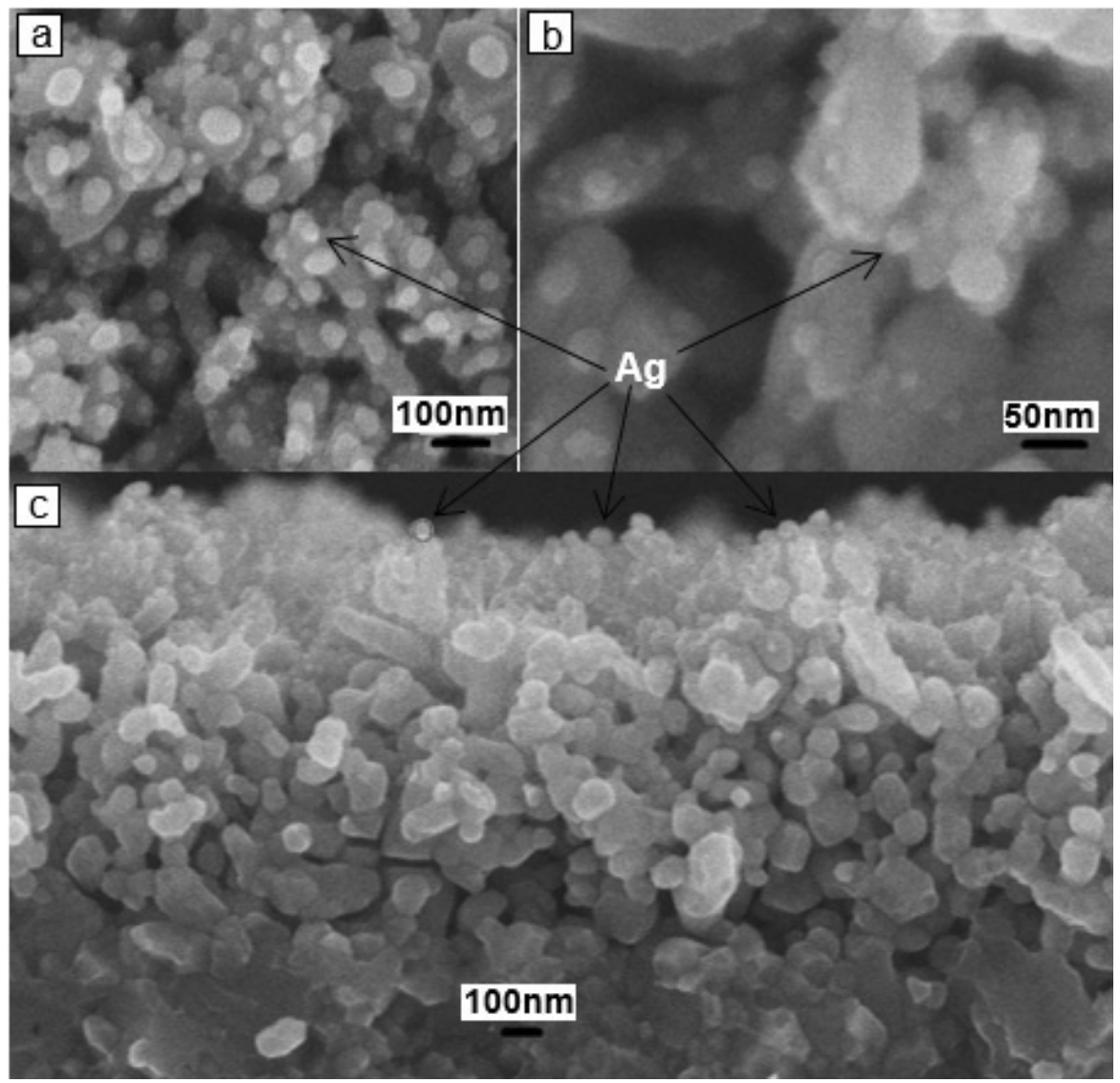

Hinh 2. Anh SEM bề mặt (a,b) và SEM cắt lớp đế SERS ZnO/Ag (c) được chế tạo bằng phuoong pháp phún xa magnetron DC 
Ngoài việc chụp ảnh SEM chúng tôi cũng đã tiến hành phân tích hàm lượng các nguyên tố trên các đế SERS bằng phương pháp EDS. Các kết quả đều cho thấy rõ sự có mặt của $\mathrm{Ag}$ trên các đế SERS. Hình EDS Mapping chứng tỏ nano Ag được phân bố đều trên bề mặt đế SERS (hình 3).

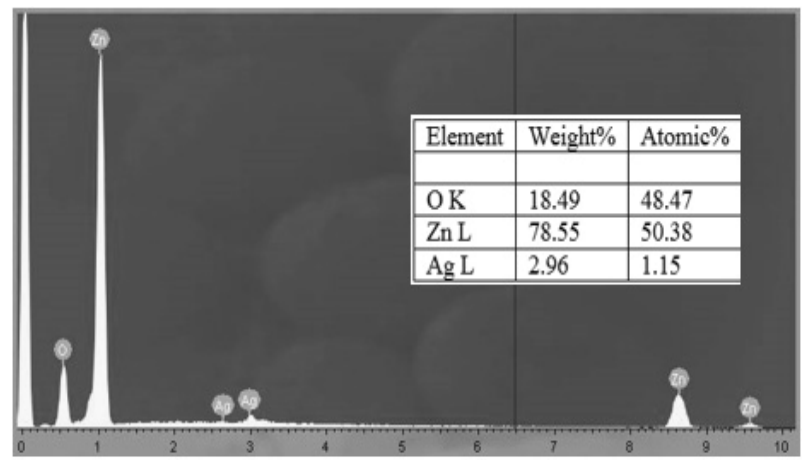

Electron Energy (keV)

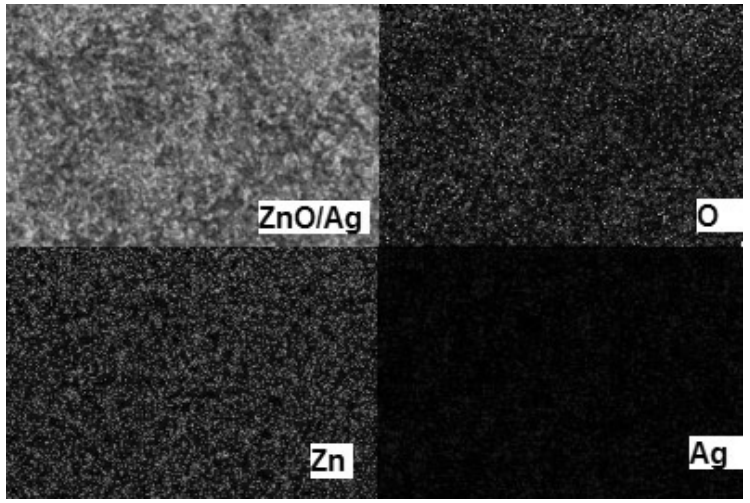

Hình 3. Anh EDS của đế SERS ZnO/Ag được chế tạo bằng phương pháp phún xa magnetron
DC. Anh UV-Vis cho phép xác định tính chất quang của đế SERS và màng ZnO xốp

Hình $4 \mathrm{a}$ cho thấy màng $\mathrm{ZnO}$ có bờ hấp thụ khoảng $400 \mathrm{~nm}$, trong khi đó đế SERS hấp thụ ánh sáng khả kiến mạnh hơn màng $\mathrm{ZnO}$, đỉnh hấp thụ ở vùng bước sóng 400 - $412 \mathrm{~nm}$, đặc trưng của nano $\mathrm{Ag}$, và bờ hấp thụ của đế SERS dịch về bước sóng dài.

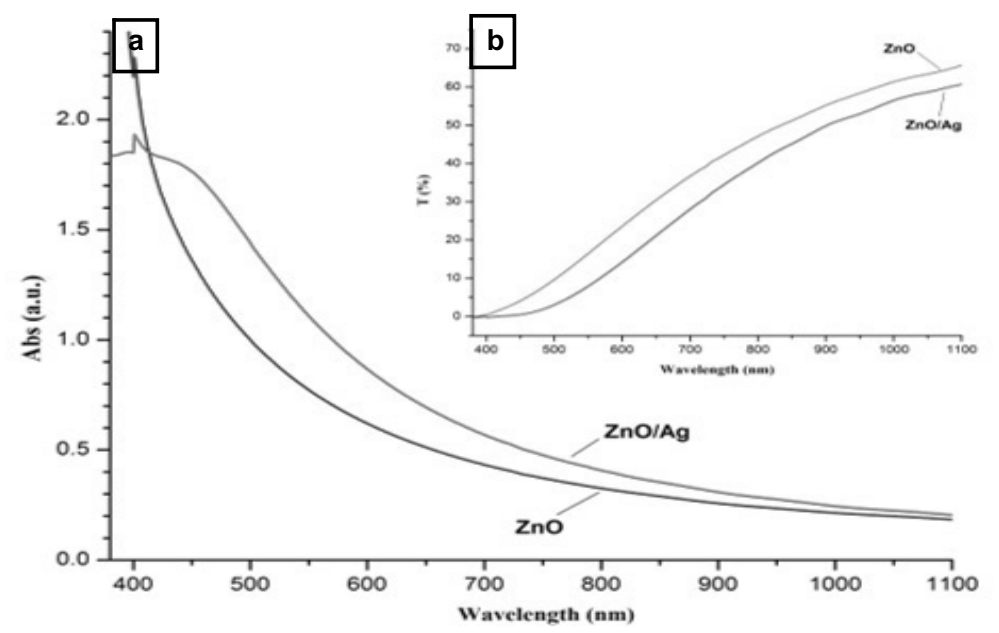

Hình 4. Phổ hấp thu (a) và phổ truyền qua (b) của $\mathrm{ZnO}$ và $\mathrm{ZnO} / \mathrm{Ag}$ được chế tạo bằng phuoong pháp phún xa magnetron $D C$

Sau khi chế tạo thành công đế SERS $\mathrm{ZnO} / \mathrm{Ag}$, chúng tôi tiến hành khảo sát sự tăng cường tín hiệu SERS của đế $\mathrm{ZnO} / \mathrm{Ag}$, chất được dùng để thử là Rhodamine $6 \mathrm{G}$.

Để so sánh độ khuếch đại, chúng tôi tiến hành đo phổ Raman của Rhodamine $6 \mathrm{G}$ nồng độ $1 \mathrm{M}$ trên đế thủy tinh trần, Rhodamine $6 \mathrm{G}$ nồng độ thấp $10^{-5} \mathrm{M}$ trên đế $\mathrm{ZnO}$, đế $\mathrm{Ag}$ và đế $\mathrm{SERS} \mathrm{ZnO} / \mathrm{Ag}$. Kết quả trên hình 5 cho thấy đối với đế thủy tinh trần, tín hiệu Raman chỉ thu được Rhodamine $6 \mathrm{G}$ ở nồng độ cao. Đối với đế $\mathrm{ZnO}$, không thu được tín hiệu Raman ở nồng độ $10^{-5} \mathrm{M}$. Đối với màng $\mathrm{Ag}$ thì đã khuếch đại được tín hiệu với nồng độ thấp $10^{-5} \mathrm{M}$. Đế SERS với sự kết hợp của màng bán dẫn $\mathrm{ZnO}$ và nano $\mathrm{Ag}$ đã cho tín hiệu Raman khá tốt ở nồng độ thấp $10^{-5} \mathrm{M}$. Các đỉnh phổ đặc trưng của Rhodamine $6 \mathrm{G}$ tại $609 \mathrm{~cm}^{-1}, 771 \mathrm{~cm}^{-1}, 1125 \mathrm{~cm}^{-1}, 1185 \mathrm{~cm}^{-1}, 1311$ $\mathrm{cm}^{-1}, 1360 \mathrm{~cm}^{-1}, 1510 \mathrm{~cm}^{-1}, 1575 \mathrm{~cm}^{-1}, 1650 \mathrm{~cm}^{-1}$ (Hình 5a).

l2 | Tạp chí KIỂM NGHIỆM VÀ AN TOÀN THỰC PHẨM (Số 4-2019) 

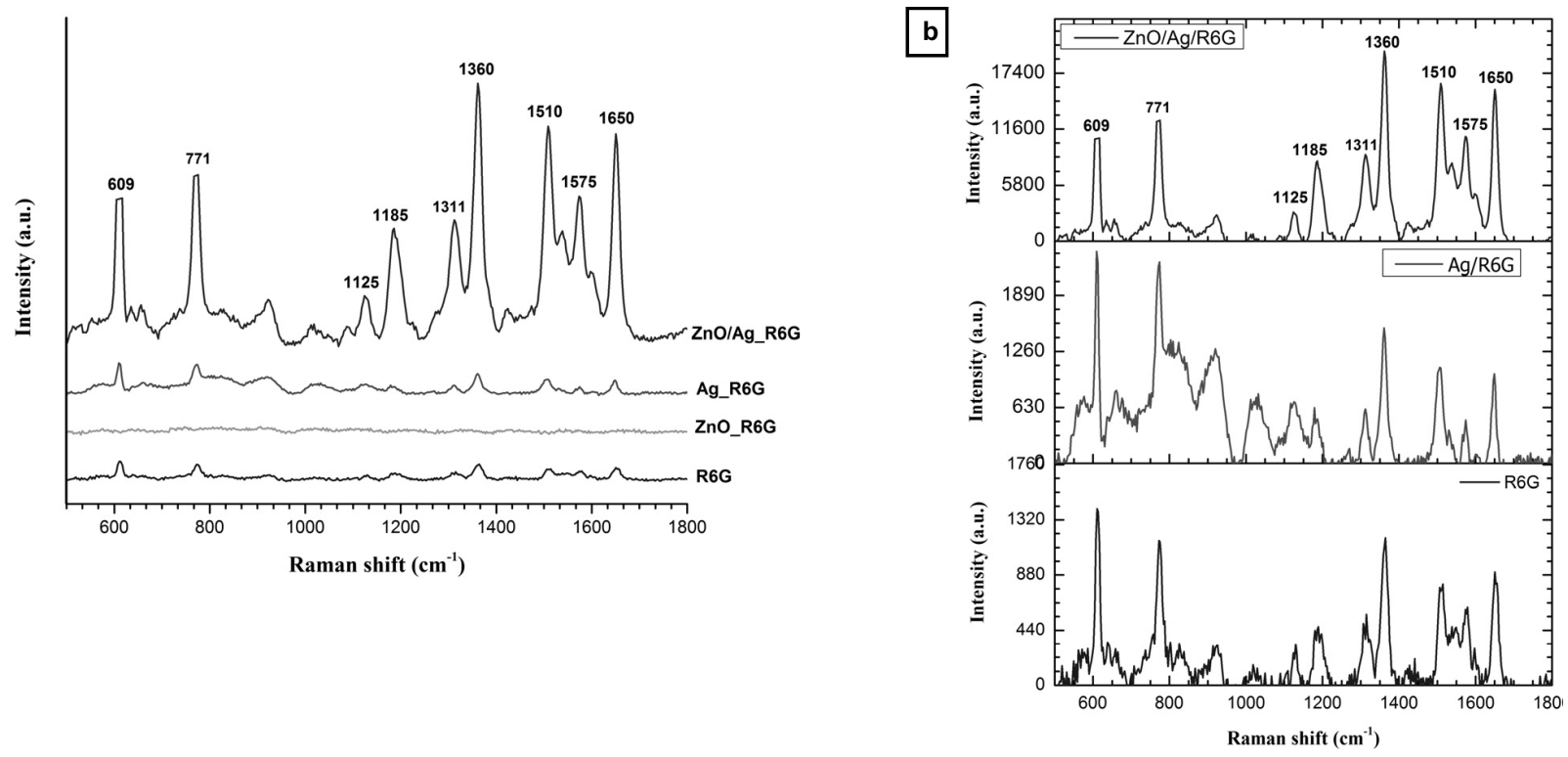

Hình 5.

a) So sánh cuờng độ bức xa Raman của Rhodamine $6 G$ trên đế thuỷ tinh trần (1M), đế $\mathrm{ZnO}\left(10^{-5} \mathrm{M}\right)$, đế $\mathrm{Ag}\left(10^{-5} \mathrm{M}\right)$ và đế SERS $\mathrm{ZnO} / \mathrm{Ag}\left(10^{-5} \mathrm{M}\right)$

b) Cương độ bức xa Raman của Rhodamine $6 \mathrm{G}$ trên đế thuỷ tinh trần (1M), đế Ag $\left(10^{-5} \mathrm{M}\right)$ và đế SERS ZnO/Ag $\left(10^{-5} \mathrm{M}\right)$ được sư dụng để tính hệ số EF

Để đánh giá hiệu quả của đế $\mathrm{SERS} \mathrm{ZnO} / \mathrm{Ag}$ được chế tạo bằng phương pháp phún xạ magnetron DC, chúng tôi tính chỉ số tăng cường Raman (Enhancement Factor-EF) theo công thức [2]:

$$
\mathrm{EF}=\frac{I_{\text {sers }} / C_{\text {sers }}}{b_{\text {base }} / C_{\text {base }}}
$$

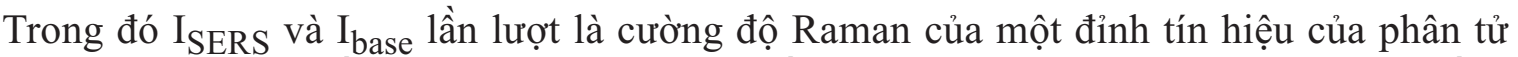
Rhodamine $6 \mathrm{G}$ khi có đế $\mathrm{SERS}$ và khi không có đế $\mathrm{SERS}, \mathrm{C}_{\mathrm{SERS}}$ và $\mathrm{C}_{\mathrm{base}}$ tương ứng là nồng độ của Rhodamine $6 \mathrm{G}$ trên bề mặt đế $\mathrm{SERS}$ và nồng độ chuẩn của Rhodamine $6 \mathrm{G}$ khi không có đế SERS. Trong trường hợp này chúng tôi chọn đỉnh ở $1360 \mathrm{~cm}^{-1}$ để tính $\mathrm{EF}$.

Dựa vào hình $5 \mathrm{~b}$ để tính chỉ số tăng cường $\mathrm{EF}$ đối với đế $\mathrm{Ag}$ là $10^{5}$ còn đối với đế SERS $\mathrm{ZnO} / \mathrm{Ag}$ là $2 \cdot 10^{6}$. Kết quả cho thấy đế SERS đã làm tăng cường độ tín hiệu Raman gấp hơn 20 lần so với đế $\mathrm{Ag}$. Như vậy chúng ta thấy, đế $\mathrm{SERS} \mathrm{ZnO} / \mathrm{Ag}$ kết hợp với phương pháp quang phổ Raman vừa có thể phát hiện (định tính) các loại hóa chất qua các đỉnh phổ Raman đặc trưng của chúng, vừa có thể định lượng phát hiện nồng độ hóa chất rất nhỏ. Chúng ta hoàn toàn có thể sử dụng đế SERS $\mathrm{ZnO} / \mathrm{Ag}$ để phân tích nhiều loại hóa chất khác với nồng độ thấp khoảng ppm, chẳng hạn như các loại hợp chất bảo vệ thực vật còn tồn dư trong các loại trái cây sau thu hoạch như Cartap, Abamectin...

\section{KẾT LUẬN}

Chúng tôi đã chế tạo được đế SERS $\mathrm{ZnO} / \mathrm{Ag}$ bằng phương pháp phún xạ magnetron $\mathrm{DC}$ nhằm phát hiện ra các hóa chất tồn dư (Rhodamine) với nồng độ rất nhỏ có trong thuốc bảo vệ thực vật hoặc nhuộm màu thực phẩm. Kết quả thu được cho thấy hình thái cấu trúc của các hạt $\mathrm{Ag}$ bám dính và phân bố đều trên bề mặt lớp màng $\mathrm{ZnO}$ xốp và hệ số tăng cường tín hiệu Raman lên đến $2.10^{6}$ lần. Trong công nghệ SERS, chỉ số $\mathrm{EF}$ ở đây được đánh giá khá tốt. Đế SERS 
$\mathrm{ZnO} / \mathrm{Ag}$ được sử dụng như bộ cảm biến (sensor) ngoài việc phát hiện ra Rhodamine $6 \mathrm{G}$ còn phát hiện được các chất khác như hoạt chất Abamectin hay Cartap có trong thuốc trừ sâu sinh học thế hệ mới. Với kết quả bước đầu này, chúng tôi sẽ tiến hành lấy 30 mẫu thực phẩm (ruốc, ớt, hạt dưa) và ứng dụng đế $\mathrm{SERS} \mathrm{ZnO} / \mathrm{Ag}$ bằng phương pháp phún xạ magnetron $\mathrm{DC}$ nhằm phát hiện Rhodamin $6 \mathrm{G}$.

Lò̀i cảm ơn: Nhóm nghiên cứu chân thành cảm ơn sụ tài trợ của đề tài Khoa học và Công Nghệ Độc lập Cấp Quốc Gia 2019, mã số: ĐTĐL.CN-04/19.

\section{TÀI LIỆ THAM KHẢO}

1. Huỳnh Thành Đạt, (2004), “Quang phổ Raman”, Nhà xuất bản Đại học Quốc gia thành phố Hồ Chí Minh, 25.

2. Eric Le Ru, Pablo Etchegoin, (2009), "Principles of surface Enhanced Raman Spectroscopy", Elsevier Radarweg 29, PO Box 211, 1000 AE Amsterdam, The Netherlands Linacre House, Jordan Hill, Oxford OX2 8DP, UK,Ch1, 4.

3. Haibin Tang, Guowen Meng, Qing Huang, Zhuo Zhang, Zhulin Huang, and Chuhong Zhu, (2012), "Arrays of Cone-Shaped ZnO Nanorods Decorated with Ag Nanoparticles as 3D Surface-Enhanced Raman Scattering Substrates for Rapid Detection of Trace Polychlori nated Biphenyls", 2012, WILEY-VCH Verlag GmbH \& Co. KGaA, Weinheim, Adv. Funct. Mater, 22, 218 - 224.

4. Javier Garcia Martinez (2018), "Plasmonic Materials. Light-controlled nanomaterials are revolutionizing sensor technology", Article Scientific Americian Arabic.

5. Lili Yang, Yong Yang, Yunfeng Ma, Shuai Li, Yuquan Wei, Zhengren Huang and Nguyen Viet Long, (2017), "Fabrication of Semiconductor ZnO Nanostructures for Versatile SERS Application", Nanomaterials, 7, 398; doi:10.3390/nano7110398.

6. Monika Kwoka, Barbara Lyson-Sypien, Anna Kulis , Monika Maslyk , Michal Adam Borysiewicz, Eliana Kaminska and Jacek Szuber, 2018, "Surface Properties of Nanostruc tured, Porous $\mathrm{ZnO}$ Thin Films Prepared by Direct Current Reactive Magnetron Sputtering”, Materials, 11, 131.

7. Marco Laurenti and Valentina Cauda, (2018), "Porous Zinc Oxide Thin Films: Synthesis Approaches and Applications", Coatings 2018, 8, 67.

8. Maosen Yang, Jing Yu, Fengcai Lei, Hang Zhou, Yisheng Wei, Baoyuan Man, Chao Zhang, Chonghui Li, Junfeng Ren, Xiaobo Yuan, (2017), "Synthesis of low-cost 3D-porous $\mathrm{ZnO} / \mathrm{Ag}$ SERS-active substrate with ultrasensitive and repeatable detectability", Sensors and Actuators B. https://doi.org/10.1016/j.snb.2017.09.197.

9. Yanjun Liu, Chunxiang Xu, Junfeng Lu, Zhu Zhu, Qiuxiang Zhu, A. Gowri Manohari, Zengliang Shi, (2017), "Template-free Synthesis of Porous ZnO/Ag Microspheres as Recyclable and Ultra-sensitive SERS Substrates", APSUSC 36763.

10. Sanghwa Lee and Jun Ki Kim, (2019), "Surface-Enhanced Raman Spectroscopy (SERS) Based on ZnO Nanorods for Biological Applications". DOI: http://dx.doi.org/10.5772/ intechopen.84265. 


\section{Summary}

FABRICATION OF SURFACE-ENHANCED RAMAN SCATTERING - SERS ZnO NANOSTRUCTURED/ NANO Ag FOR RHODAMINE 6GDETECTION

Huyen Le Thi Minh', Giang Nguyen Huong', Tuan Dao Anh ${ }^{3}$, Tuan Pham Tran ${ }^{3}$ Uy Vu Hoang ${ }^{3}$, Viet Nguyen Hoang ${ }^{3}$, Hung Le Vu Tuan ${ }^{3}$

${ }^{1}$ Faculty of Fundamental Sciences, University of Medicine and Pharmacy in Ho Chi Minh City

${ }^{2}$ Ho Chi Minh City Center for the Quality Control of Food, Drug and Cosmetics, Food Safety Management Authority of Ho Chi Minh City

${ }^{3}$ Faculty of Physics - Engineering Physics, University of Sciences, National University Ho Chi Minh City

In recent years, scientists have been focusing on ways to enhance Raman signals by surface plasmon resonance effect - SERS. This method allows detections of trace pesticide residues, because it helps identifying molecules at very low concentrations without destroying or discoloring samples. Therefore, the SERS method opens a new step in the study of physics, materials science, medical diagnostics, identification of new drugs, etc. In this study, nanostructured $\mathrm{ZnO}$ material were manufactured by DC magnetron sputtering method. The Ag nanoparticles were, then, modified on $\mathrm{ZnO}$ surface by DC magnetron sputtering method. The material was proved to be able to improve the detection of Rhodamine 6G reagent at trace levels. The enhancement factor of SERS was of more than $10^{6}$.

Keywords: SERS, Rhodamine 6G, DC magnetron sputtering method, nano Ag, ZnO. 